\title{
Huellas de la reestructuración capitalista. Un análisis de la transformación urbana de la Región Metropolitana de Buenos Aires, Argentina
}

\section{Traces of capitalist restructuring. An analysis of the urban transformation of the Metropolitan Region of Buenos Aires, Argentina}

\author{
María Cecilia Zapata*
}

\begin{abstract}
Resumen
Cada fase de desarrollo del sistema capitalista dejó huellas en la configuración territorial de la Región Metropolitana de la Ciudad de Buenos Aires, Argentina. Este artículo tiene por objetivo caracterizar y analizar las transformaciones en la estructura urbana de dicha región entre los años del modelo neoliberal (1976-2001) y del neodesarrollismo extractivista (desde 2001), identificando rupturas y continuidades entre ambos modelos de acumulación capitalista y sus impactos a escala territorial. Para ello, se recurrió a una metodología cualitativa, a partir de la reconstrucción de datos provenientes de fuentes secundarias y entrevistas informales con referentes estudiosos de la temática.
\end{abstract}

Palabras clave: ciudad; transformación urbana; gestión urbana; neoliberalismo; neodesarrollismo extractivista; régimen de acumulación.

\begin{abstract}
Each phase of development of the capitalist system left traces in the territorial configuration of the Metropolitan Region of the City of Buenos Aires, Argentina. The objective of this article is to characterize and analyze the transformations in the urban structure of this region between the years of the neoliberal model (1976-2001) and the extractivist neo-development (since 2001), identifying ruptures and conti-

* Universidad de Buenos Aires, Instituto de Investigaciones Gino Germani / Consejo Nacional de Investigaciones Científicas y Técnicas. Dirección: Pres. José Evaristo Uriburu 950, C1114 AAD, Buenos Aires, Argentina. Correo: ceciliazapata@gmail.com ORCID: http:// orcid.org/0000-0003-0580-6938
\end{abstract}


nuities between both capitalist accumulation models and their impacts at territorial scale. For this purpose, a qualitative methodology was used, based on the reconstruction of data from secondary sources and informal interviews with scholarly referents of the subject.

Keywords: city; urban transformations; urban management; neoliberalism; extractivist neo-development; accumulation regime.

\section{Introducción}

Cada fase de desarrollo ${ }^{1}$ del capitalismo argentino ${ }^{2}$ dejó marcas territoriales en la configuración de la Región Metropolitana de Buenos Aires (RMBA), ${ }^{3}$ pues el territorio se configuró como soporte material para su despliegue, pero atravesado por relaciones de poder, dominio y apropiación entre diversos actores que produjeron y reprodujeron el espacio. Tal como argumentaba Harvey (2000), el capitalismo, como modo de producción, logró sobrevivir a sus diversas crisis, en parte, a partir del uso del espacio como estrategia de recreación de las relaciones sociales que lo sustentan. Así, el control sobre la producción y la apropiación del territorio y las relaciones espaciales tiene una importancia estratégica para el control de otros medios de producción.

En los procesos de reconfiguración del capitalismo, tanto el Estado (garante de las relaciones de producción capitalistas) como el mercado y la sociedad disputan un rol directriz en el proceso de producción y reestructu-

\footnotetext{
${ }^{1}$ Retomando el concepto de Brailovsky y Foguelman, 2004, se entiende aquí por fase de desarrollo a un periodo de tiempo que se caracteriza por cierta forma de ocupación del territorio, de determinadas relaciones sociales de producción, de conocimientos y tecnologías, y de conflictos sociales. Esta herramienta conceptual nos permite comprender los fenómenos sociales de determinado tiempo histórico en un espacio específico, pues sostenemos que las políticas económicas, sociales, culturales, ambientales, territoriales o de población poseen una fuerte coherencia en cada uno de los periodos de tiempo durante los cuales perdura un modelo de país. La interrelación existente entre los fenómenos sociales de cada fase es lo que la define como tal.

${ }^{2}$ Las fases de desarrollo capitalistas que se pueden identificar en Argentina (de manera analítica) son: los primeros años de conformación del Estado argentino y la inserción del país en la división internacional del trabajo (1810-1930), la industrialización sustitutiva de importaciones y el estado de bienestar (1930-1976), el neoliberalismo de la modernización periférica (desde 1976 hasta 2001) (Brailovsky y Foguelman, 2004) y el neodesarrollismo extractivista (desde 2001) (López y Vértiz, 2012; Féliz y López, 2010; Svampa, 2011).

${ }^{3}$ La RMBA es un conglomerado urbano mayor que el Área Metropolitana de Buenos Aires (AMBA), conformada por la Ciudad Autónoma de Buenos Aires y los 40 partidos de la Provincia de Buenos Aires. Según el Censo Nacional de Población, Hogares y Viviendas 2010 , la población de la RMBA conformaba el $37 \%$ de la población del país. Más adelante se caracteriza la región.
} 
ración urbana del territorio. Pero a lo largo de la historia de Argentina, fue el mercado, a través de distintos promotores urbanos privados, el que guio los diversos y sucesivos procesos de construcción territorial de la RMBA, y lo hizo -fiel a su naturaleza- desde una lógica de maximización de la ganancia (Herzer y Pírez, 1994; Abramo, 2003; Rodríguez, 2005), ${ }^{4}$ a partir de usos especulativos del suelo y su valor económico. Esta dinámica convirtió al suelo urbano en una mercancía escasa y costosa, y las consecuencias a escala territorial se expresaron en marginación, degradación y desequilibrios del espacio urbano (Sánchez, 2012, p. 3).

Por su parte, el Estado, en cada fase del desarrollo capitalista, se constituye en un dispositivo fundamental para la localización (y relocalización) de personas, recursos, actividades e instituciones en la ciudad (Rousseau, 2009; Davidson, 2008). Ya sea por acción o por omisión (Oszlak y O’Donnell, 1981), el Estado argentino, de manera invariable en las distintas fases, desempeñó un rol ausente en la tarea de planificación y/o control del desarrollo urbano, aunque subsidiario a los intereses del mercado (vale aclarar, en contextos territorializados de fuerte disputa y de correlaciones de fuerza de clases). A lo largo de la historia, fue el Estado capitalista quien propició los marcos legales normativos, e incluso la infraestructura urbana necesaria para la reestructuración de la ciudad.

$\mathrm{Y}$ aquellos sectores que no accedieron a la vivienda y a la ciudad a través del mercado o del Estado, lo hicieron guiados por una lógica de estricta necesidad (Herzer y Pírez, 1994; Abramo, 2003; Rodríguez, 2005) mediante modalidades de hábitat popular mayormente autoproducidas: conventillos, inquilinatos, hoteles-pensión, villas y asentamientos, e incluso la misma ciudad se convirtió en dormitorio para miles de personas en situación de calle.

El derrotero de las sucesivas configuraciones territoriales de las distintas fases de desarrollo del capitalismo en Argentina dejó por resultado una mezcla de expansión territorial fragmentada y geográficamente desigual, con un fuerte componente de precarización de la calidad de vida urbana de la RMBA. Pero lo que interesa en este artículo es prestar atención

${ }^{4}$ Estos autores identifican tres lógicas de producción de ciudad: la lógica del mercado, que posibilita el acceso al suelo y a la vivienda desde un intercambio mercantil y la generación de ganancia a partir de negocios con el suelo; la lógica estatal, la cual, a través de la normativa urbana y la ejecución de políticas habitacionales, resuelve o agudiza el problema de la falta de vivienda y la accesibilidad a la ciudad de los sectores populares; y la lógica de la necesidad de aquellos actores sociales que no resuelven sus necesidades de hábitat a través del mercado o las políticas estatales, y que recurren a otras estrategias de acceso al suelo y/o a la vivienda (algunas de éstas son las ocupaciones directas de tierras o inmuebles privados o públicos vacantes o en desuso). 
a las transformaciones que sufrió el territorio específicamente en las últimas décadas, durante la transición entre el modelo neoliberal (1976-2001) y el neodesarrollista extractivista (desde 2001). Los primeros años del siglo XXI dieron cuenta de un re aggiornamento del ciclo de acumulación del capital sobre las bases previamente creadas, pero al mismo tiempo se consolidó una nueva dependencia vinculada a la producción de commodities orientadas a la exportación (López y Vértiz, 2012; Féliz y López, 2010), a partir de lógicas y prácticas extractivistas (en donde el suelo urbano asume un rol fundamental). Esto dio lugar a nuevas asimetrías económicas, políticas y ambientales que tuvieron expresión en el ámbito nacional, pero también regional y global, y sobre todo -de nuestro interés- con expresión a escala territorial.

Con este escenario, el objetivo del artículo es caracterizar y analizar las transformaciones sociales y urbanas de la Región Metropolitana de Buenos Aires entre los años del modelo neoliberal (1976-2001) (Brailovsky y Foguelman, 2004) y los años del neodesarrollismo extractivista (desde 2001) (López y Vértiz, 2012; Féliz y López, 2010; Svampa, 2011), identificando rupturas y continuidades entre ambos modelos y sus impactos a escala territorial. Con el fin de sistematizar información dispersa sobre estos procesos, aquí se analizan estas transformaciones a partir de tres cambios observables a escala geográfica: cambios en el modelo productivo, cambios en la morfología urbana (inclusive de infraestructura urbana a escala ciudad) y cambios en las modalidades de asentamiento poblacional.

Por las características del objeto de análisis, se recurrió a una metodología cualitativa de abordaje basada en la recuperación de fuentes secundarias, como bibliografía proveniente de la historiografía, la economía política, la geografía y los estudios urbanos, informes de gestión y artículos periodísticos; así como de fuentes primarias, mediante la consulta a algunos referentes temáticos sobre el tema. Los datos recuperados se procesaron a partir de la definición de dimensiones de análisis que permitieron clasificar los datos obtenidos. El análisis fue temático.

Primeramente, se caracteriza sociodemográficamente la Región Metropolitana de Buenos Aires. Luego, siguiendo un criterio cronológico, se realiza una somera descripción de algunas particularidades de ambos modelos de producción, el neoliberal (1976-2001) y el neodesarrollismo extractivista (desde 2001) para transparentar los perfiles económicos y productivos de cada uno de ellos y, de manera relacional, se analizan las transformaciones sociales y urbanas que cada uno de estos modelos productivos necesitó a escala territorial para su desarrollo y el tipo de ciudad que configuró. Por último, se consignan algunas reflexiones finales. La hipótesis que atraviesa al 
artículo es que cada uno de estos proyectos socioeconómicos de país desplegó un modelo productivo que dejó huellas explícitas a escala territorial, readaptando la estructura urbana a sus propósitos, donde el mercado guio este proceso, mientras el Estado y los distintos sectores sociales se "acomodaron" en los intersticios de dicha reestructuración. No obstante, independientemente de las reformulaciones del modelo de acumulación de las últimas décadas, la lógica de producción del suelo urbano en la RMBA no sufrió modificaciones sustanciales entre el modelo neoliberal y el neodesarrollismo extractivista. Se intentará demostrar que, por el contrario, se fortalece la absorción de excedente de capital y trabajo a través del impulso a nuevas transformaciones urbanas, en donde el Estado se limita a una intervención ex post.

\section{La Región Metropolitana de Buenos Aires: una foto censal}

Según el Censo de Población, Hogares y Viviendas de 2010, la RMBA cuenta con 14819137 personas, que concentran al 37\% de la población argentina en un espacio que representa menos del $1 \%$ del territorio nacional; ello configura una regionalización que comprende a la Ciudad de Buenos Aires (CABA) (con 2891082 habitantes) y a 40 partidos de la Provincia de Buenos Aires ${ }^{5}$ (con los restantes 11928055 habitantes), como se puede apreciar en el Mapa 1. Además, la región se divide en tres coronas de urbanización, en las cuales más del $75 \%$ de la población se concentra en los partidos de la primera y segunda coronas (área también conocida como el Gran Buenos Aires), y se diluye su concentración hacia la tercera corona, con menos del $5 \%$. Sólo la CABA contiene a casi el $20 \%$ de la población de la RMBA. Por otra parte, los partidos de esta región (40 municipios) aglutinan el $80 \%$ del total de la población de la Provincia de Buenos Aires, en un territorio provincial que representa a menos del $4 \%$.

La mancha urbana de la RMBA abarca una superficie de $2440 \mathrm{~km}^{2}$ y en su territorio se produce alrededor del $52 \%$ del producto bruto interno (PBI) del país, lo que da cuenta del dinamismo de dicha región (Subsecretaría de Urbanismo y Vivienda, 2007).

${ }^{5}$ La Región Metropolitana de Buenos Aires está compuesta por la Ciudad de Buenos Aires más 40 partidos: Almirante Brown, Avellaneda, Berazategui, Berisso, Brandsen, Campana, Cañuelas, Ensenada, Escobar, Esteban Echeverría, Exaltación de la Cruz, Ezeiza, Florencio Varela, General Las Heras, General Rodríguez, General San Martín, Hurlingham, Ituzaingó, José C. Paz, La Matanza, La Plata, Lanús, Luján, Lomas de Zamora, Malvinas Argentinas, Marcos Paz, Merlo, Moreno, Morón, Pilar, Presidente Perón, Quilmes, San Fernando, San Isidro, San Miguel, San Vicente, Tigre, Tres de Febrero, Vicente López y Zárate. 


\section{Mapa 1}

Partidos y división en coronas

de la Región Metropolitana de Buenos Aires
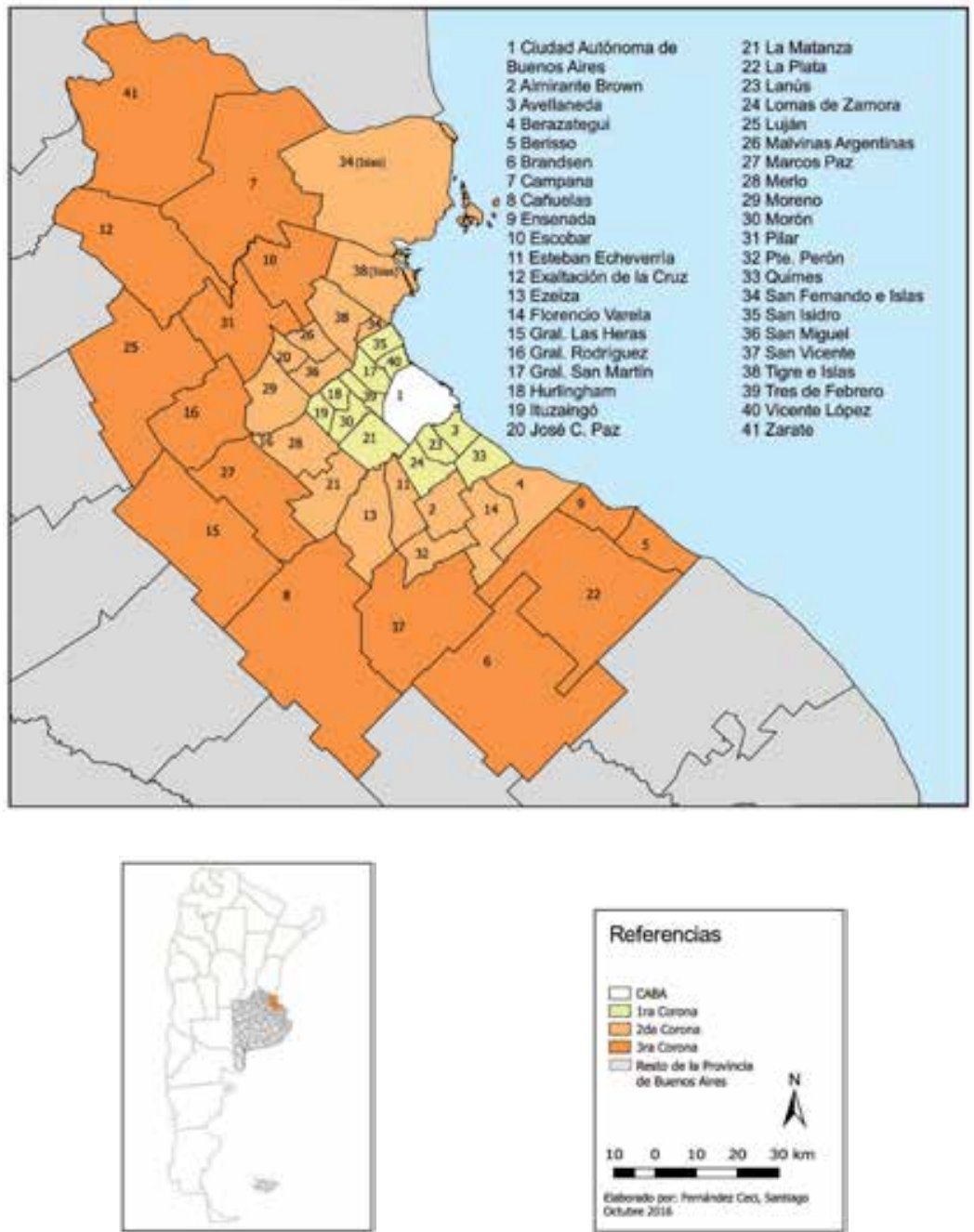

Fuente: Instituto del Conurbano, 2016.

Estudios Demográficos y Urbanos, vol. 35, núm. 3 (105), sept.-dic., 2020, pp. 663-694 http://dx.doi.org/10.24201/edu.v35i3.1892 
En cuanto a su crecimiento poblacional, la CABA constata una cantidad de población estable desde hace seis décadas (en el periodo intercensal 2001-2010 sólo aumentó en 115000 habitantes), mientras que la RMBA tuvo 1500000 habitantes nuevos (un incremento del 12.5\% superior a la media nacional). Esta fuerte densificación del conurbano se explica en gran medida por los partidos de la primera y segunda coronas del Gran Buenos Aires, los cuales tuvieron un crecimiento de 1340789 habitantes. No obstante, específicamente la primera corona sigue una tendencia muy similar a la $\mathrm{CABA}$, estancando su aumento poblacional en las últimas dos décadas, mientras que la segunda corona aumenta su densidad de manera sostenida desde 2001 (manifestando la mayor tasa de crecimiento intercensal). La tercera corona la sigue muy por detrás, pero con un aumento leve sostenido. Como se verá más adelante, estas variaciones están en estrecha vinculación con las transformaciones urbanas que sufrió el territorio desde los años setenta, con la conversión de la ciudad en una urbe neoliberal y la profundización de algunas tendencias durante el neodesarrollismo extractivista.

El censo 2010 también arrojó que casi 11\% de los hogares (306217 hogares) vive en situación de déficit habitacional, y sólo el 69\% de la población tiene cobertura de agua potable. Según la asociación civil Techo (2016), la población que vive en villas y asentamientos se concentra en el $2.6 \%$ de la superficie de la región, mientras que el $2 \%$ más rico de la población ocupa el $20 \%$ del suelo urbanizado de la RMBA, en barrios privados.

\section{La ciudad neoliberal: reacomodando el territorio}

Según García Delgado (1994), la última dictadura cívico-militar, mediante el sangriento Proceso de Reorganización Nacional (1976-1983), propuso reestablecer el "orden" a partir de la recuperación del monopolio del ejercicio de la fuerza para sedimentar lo que sería el proyecto neoliberal en Argentina. Entre sus medidas, destacó la desarticulación (y descentralización) del Estado (y la consecuente desaparición de muchas de las políticas estatales orientadas a los sectores populares), la inserción de Argentina en la globalización, la apertura de la economía a partir de la desregulación estatal, el empoderamiento del sector económico vinculado al capital financiero y, en consecuencia, un fuerte proceso de desindustrialización del país. Este régimen autoritario se caracterizó por la exclusión del consenso como medio para implementar políticas públicas y la exaltación de estructuras jerárquicas verticalistas para el ejercicio del poder. Se disolvieron el Congreso Nacional, las legislaturas pro- 
vinciales y los Consejos de Deliberantes, se removió a la Corte Suprema, se prohibió la acción política y gremial, y se eliminaron los derechos fundamentales de la población (González, 2002). No obstante, las denuncias nacionales e internacionales en materia de violación de los derechos humanos y la crisis económica comenzaron a calar profundo a inicios de los años ochenta. Con la recuperación democrática de 1983, Argentina reconquistó los derechos constitucionales, pero el modelo económico neoliberal continuó vigente, y en la década del noventa logró su consolidación.

El nuevo modelo económico, basado en la especulación financiera, provocó que los productores giraran sus inversiones, con consecuencias como el cierre masivo de industrias nacionales y, por ende, se transfirieron recursos al exterior. Esto fue concomitante con una regresiva distribución del ingreso, con la desaparición del salario como regulador de la economía (y estimulador de un mercado interno activo). La desindustrialización y la reapertura insertaron al país en una nueva división internacional del trabajo, globalizada, en donde los nuevos rectores de la economía fueron los intereses del capital transnacional. En esta nueva etapa, el territorio no sólo fue soporte de los cambios que se produjeron sobre él, sino que pasó a ser un bien más con valor de cambio en el mercado, impactando en la forma en la que se distribuyen en el espacio las fábricas, las herramientas, las materias primas de producción, así como los trabajadores y sus familias.

En este marco, y atravesadas por la revolución científico-tecnológica de fines del siglo XX (Argumedo, 2000), las transformaciones de la estructura productiva y del mercado de trabajo fueron totales. Nuevas tecnologías informáticas y comunicacionales permitieron aumentar a velocidades inimaginadas las transacciones comerciales y financieras, e impactaron fuertemente en las innovaciones aplicadas a la producción, las cuales posibilitaron la reducción de los tiempos de trabajo, la maximización de las ganancias, el reemplazo de los hombres trabajadores por robots trabajadores, ${ }^{6} \mathrm{y}$ la rápida instalación y desinstalación de establecimientos fabriles y de empresas en general en aquellos territorios del globo que faciliten oportunidades de acumulación (Verón, Adamo y Tobio, 1998). A partir de lo anterior, el capital transnacional tiende a instalarse en países de gran flexibilidad en materia normativa, con mano de obra no sindicalizada, con índices de desocupación

${ }^{6}$ Lo cual también genera un cambio en el tipo de trabajador necesario en este momento histórico, pues ya no va a ser el trabajador especializado en una etapa mínima del proceso productivo, en donde su actividad se caracteriza por la realización de una tarea por repetición, sino que se trata de trabajadores técnicos que manejen y controlen instrumentos automatizados (Argumedo, 2000; Verón, Adamo y Tobio, 1998). 
lo suficientemente elevados que licuen reclamos de derechos laborales y estimulen a la baja los salarios. Todo esto impulsó una hiperespecialización productiva, en donde las grandes empresas, en aras de abaratar costos, producen parte de un producto en una nación, otra parte en un segundo país, ensamblan en un tercero y comercializan en otro.

En este escenario, Argentina vuelve a transitar a un proceso de reprimarización de su economía con prácticas extractivistas, insertándose nuevamente en el mundo globalizado como un país agroexportador, pero ya no de maíz y carnes, sino fundamentalmente de soja [soya], girasol, recursos minerales e hidrocarburos.

En materia industrial, tanto el modelo productivo como sus patrones de localización fueron fuertemente reformados. La desindustrialización y la especialización productiva, propias del neoliberalismo, produjeron el pasaje de un esquema industrial orientado a la producción de bienes y servicios avanzados - con algún nivel de complejidad- a una industria de producción y servicios orientados al consumo. Además, se registró una tendencia a la eliminación de algunos procesos productivos en el espacio "fábrica", para distribuirlos en la ciudad metropolitana, conformando una nueva línea de montaje que articula una multiplicidad de pequeños talleres con sectores industriales más tecnificados y asociados al circuito internacional. Este cambio impactó en términos territoriales, pues bajo nuevas formas el sector productivo siguió siendo motor de cambio espacial, pero promoviendo dinámicas de crecimiento periférico a partir de la revalorización de áreas centrales del conurbano y la formación de nuevos enclaves pericentrales de actividad, favoreciendo un tipo de metropolización difusa o policéntrica (De Mattos, 1998; Ciccolella, 1999). ${ }^{7}$ Estas mutaciones impulsaron, por un lado, un proceso de estancamiento y fuerte degradación de áreas industriales tradicionales de la CABA y de los partidos de la primera corona (como Avellaneda, partido núm. 3 del Mapa 1) (Balbo, Porto y Posadas, 1996; Borello y otros, 2000; Bozzano, 1999, en Fritzsche y Vio, 2005), y por otro, el despliegue de un proceso de metropolización industrial hacia la segunda $-\mathrm{y}$ en menor medida en esta etapa- $\mathrm{y}$ la tercera coronas (véase el Mapa 1).

En las nuevas localizaciones la industria neoliberal adopta otras formas, organizándose en tecnopolos, distritos industriales y áreas-sistema, parques científicos y tecnológicos, aglomeraciones industriales planificadas

${ }^{7}$ Fundamentalmente se da a partir de la periferización de la industria hacia la tercera corona de la región y con fuerte protagonismo del eje norte, en torno al Acceso Norte, ramales Campana y Pilar. 
y just in time, sistemas institucionales territoriales, clústeres, etc. (Fritzsche y Vio, 2005). ${ }^{8}$ Las nuevas pautas de localización industrial impulsaron también el traslado de hoteles y restaurantes internacionales que, además de instalarse en las áreas centrales de la CABA, acompañaron el proceso de metropolización a partir de fuertes inversiones de capital en la periferia (por ejemplo, la zona de Pilar - partido núm. 31- o la zona de Hudson, en el partido de Berazategui ${ }^{9}$-partido núm. 4 del Mapa 1-).

Así, el suelo dejó de ser simple soporte y pasó también a ser objeto de especulación y negocio, convirtiendo a la ciudad y a su área metropolitana en un espacio atractivo para los flujos del capital transnacional. Ciccolella (1999) argumenta que se encara el tránsito de un modelo de ciudad de centro / periferia, caracterizado por un área metropolitana compacta que evoluciona en forma de "mancha de aceite" (con morfología y bordes bien definidos), a un crecimiento metropolitano en forma de red, con ciudades-regiones de bordes difusos, policéntricas, incluso consolidando en algunos casos megalópolis o archipiélagos urbanos. La ciudad neoliberal se caracteriza por un modelo de incorporación y exclusión de áreas, con fragmentación del territorio y dualización de sus sociedades.

En este proceso de reacondicionamiento del territorio, el Estado abandonó, a favor del mercado, la planificación de esta reestructuración espacial para cumplir un rol subsidiario de acondicionador y promotor de la transformación mediante la sanción de nuevas normativas urbanas y políticas públicas habilitantes. Hay que rastrear el impulso inicial de estas transformaciones territoriales en un conjunto de medidas tomadas en la última dictadura militar (1976-1983), el cual constituyó la punta de lanza para el acomodamiento de la ciudad al nuevo modelo productivo y metropolitano: la construcción de un Plan de Autopistas Urbanas, que pretendía modernizar la circulación por la ciudad; la sanción de la Ley de Locaciones Urbanas (núm. 21.342/76), que desregularizó el precio de los alquileres (provocando una oleada de desalojos y precarización de las condiciones de habitabilidad de los sectores populares); la aprobación de la Ley de Erradicación Industrial de la ciudad capital, que desplazó las industrias hacia el segundo cordón de la RMBA, con los efectos ya referidos; la creación del Cinturón Ecológico Área Metropolitana Sociedad del Estado (CEAMSE) para la disposición final de los residuos de toda la RMBA; la aprobación de nuevos

${ }^{8}$ El distrito tecnológico del barrio Parque Patricios, que actualmente promociona el gobierno de la Ciudad de Buenos Aires, es un claro ejemplo de ello. Para mayor información, véase http://www.distritotecnologico.com/buenos-aires/tag/parque-patricios/

${ }^{9}$ Para mayor información, véase https://www.lanacion.com.ar/1371205-hudson-unremanso-sureno 
marcos normativos excluyentes de los sectores populares al acceso a la ciudad (como el Decreto-Ley de Ordenamiento Territorial y Uso del Suelo en la Provincia de Buenos Aires, y el Código de Planeamiento Urbano en la ciudad capital); la reglamentación de la Circular 1050, que indexó créditos hipotecarios a montos impagables; y la erradicación de villas miseria de la CABA (Oszlak, 1991, pp.14-32). Incluso ya en los noventa, durante la consolidación del neoliberalismo en el país en democracia, se privatizó la provisión de bienes y servicios de la infraestructura urbana (como el transporte público -subterráneos, autopistas y trenes-, las comunicaciones, la producción y distribución de energía, gas, petróleo, agua y cloacas), con fuertes efectos segregatorios en la estructura urbana.

En materia de política habitacional, en un escenario neoliberal la vivienda social se configuró como un dinamizador de la economía. En este sentido, a los sectores sociales sin capacidad de acceso a un crédito bancario se les encuadró dentro de las operatorias del Fondo Nacional de la Vivienda (Fonavi), reorganizado en $1977^{10}$ para el acceso a una vivienda "llave en mano", "y a los sectores con capacidad de demostración de ingresos se les asignó una cartera de créditos operacionalizados desde el Banco Hipotecario Nacional (BHN) (Yujnovsky, 1984, p. 223). Pese a esta definición, en la CABA (la más rica del país) la inversión pública en vivienda social mostró un descenso continuo entre los años 1980 y 1992 , registrando el $0.71 \%$ del PBI en 1984 y descendiendo a $0.53 \%$ en los primeros años de la década del noventa (Zapata, 2012). Esta desatención de la problemática impulsó el surgimiento de distintas formas de producción social del hábitat por parte de los sectores populares en zonas intersticiales de la ciudad, las cuales fueron más o menos exitosas en función del grado de organización popular y la envergadura de los emprendimientos encarados. En el centro de la CABA proliferaron los alquileres informales en hoteles-pensión, se produjo una oleada de ocupaciones de inmuebles ociosos y, fundamentalmente en la

${ }^{10}$ Mediante la Ley 19.929/72 se crea el Fonavi, con recursos originados del $1.5 \%$ de las transacciones de ganado (Ley 19.876), un porcentaje de los impuestos urbanos de ese año y el $2.5 \%$ de aportes patronales. En 1977, con la Ley 21.581, se reorganiza el fondo remarcando el objetivo de producir viviendas para familias de escasos recursos, y ejecutar obras de urbanización, de infraestructura y de equipamiento comunitario, entre otros asuntos; asimismo, pasa a estar financiado por el $5 \%$ de los aportes patronales, el 20\% de aportes autónomos y la recuperación de inversiones (Zapata, 2012).

${ }^{11} \mathrm{Si}$ bien las intervenciones del Fonavi contemplaban una variedad de problemáticas que componen el déficit habitacional, sus recursos se canalizaron casi exclusivamente a la construcción de viviendas nuevas "llave en mano" (Cuenya, 2000, p. 4). En Zapata (2017) se pueden consultar los impactos socioterritoriales de tales políticas. 
zona sur de la ciudad -con excepción de la Villa $31-{ }^{12}$ y en los partidos de la primera corona del conurbano, se repoblaron las villas y los asentamientos ${ }^{13}$ (Rodríguez, 2005; Cravino, 2006; Cravino, Del Río y Duarte, 2008; Zapata y Belluscio, 2018). En la RMBA comenzaron a producirse ocupaciones de tierras organizadas de manera colectiva en los partidos de Quilmes, Almirante Brown (partidos núm. 33 y 2, respectivamente en el Mapa 1, zona sur), La Matanza, Morón y Merlo (partidos núm. 21, 30 y 28 del Mapa 1, zona oeste), adoptando la forma de asentamientos ${ }^{14}$ (Zapata, 2012).

En la RMBA también emergieron tendencias a la metropolización de sectores de altos ingresos en nuevas urbanizaciones cerradas / privadas de residencia permanente (tales como countries, barrios cerrados, marinas, etc.), que se localizaron a lo largo de las autopistas urbanas y/o en zonas intersticiales próximas a ellas. La aparición de esta tipología de hábitat modificó las dinámicas tradicionales de asentamiento poblacional del conurbano, pues los viejos patrones de localización residencial alrededor de la red del ferrocarril (zonas que ahora quedaron reservadas para sectores medios y populares) fueron reemplazados por un patrón de localización por encapsulamiento con efectos fragmentatorios del territorio y sustentado en la utilización del automóvil como estrategia de movilidad prioritaria para este sector social. Las viviendas suntuosas, los parques cuidadosamente diseñados y los dispositivos de seguridad (muros, vigilancia computarizada, etc.) que separan físicamente a estos barrios cerrados del resto del tejido urbano (loteos económicos, villas, asentamientos, viejos centros urbanos), configuraron un nuevo paisaje urbano periférico caracterizado por situaciones de enclave (de riqueza y pobreza) con fracturas en la continuidad del espacio público (fenómeno urbano que originó, además, conflictos sociales urbanos focalizados de gran potencial). Estos nuevos patrones de localización residencial y formatos de habitación fueron además estimulados por la instalación en sus inmediaciones de grandes equipamientos comerciales, como shopping centers, centros comerciales e hipermercados financiados por capitales transnacionales. Estos nuevos dispositivos comerciales provocaron una fuerte desarticulación de los antiguos

${ }^{12}$ La Villa 31 es una de las más emblemáticas de la Ciudad de Buenos Aires por ser la más poblada de la ciudad (por aproximadamente unas treinta mil familias) y localizarse colindante a los barrios más costosos y suntuosos de la ciudad: Recoleta y Puerto Madero.

${ }^{13}$ La dictadura militar de los setenta y ochenta logró erradicar a más del $84 \%$ de la población villera porteña, desalojando a las familias hacia las provincias o países de origen.

${ }^{14}$ Merklen (1991) argumenta que los asentamientos de los años ochenta se caracterizan por haber sido gestados de manera masiva y organizados colectivamente, respetando los trazados de calle del barrio de inserción y las superficies exigidas por la normativa urbana, previendo espacios comunitarios y áreas verdes como estrategia para iniciar las gestiones de regularización de la tierra y las mejoras en las condiciones del hábitat. 
patrones de localización y estructura comercial y de consumo, pues el reequipamiento de estas áreas generó nuevas subcentralidades que disminuyeron, en términos relativos, los flujos entre periferia y centro, provocando una tendencia hacia la inmovilización de la población residente y una modificación en las pautas de movilidad cotidiana, reorientándolas hacia el interior del partido o región, y ya no hacia el centro de la CABA.

Otra nueva modalidad de hábitat, producto del neoliberalismo, fueron los "countries verticales" (en esta etapa con epicentro en la ciudad capital y como estrategia de reserva de valor). ${ }^{15}$ Se trata de conjuntos residenciales con equipamiento deportivo, de confort y dispositivos de seguridad, localizados en áreas de alto poder adquisitivo y/o zonas en procesos de renovación urbana. Estos nuevos artefactos urbanos generaron un fuerte impacto en la trama metropolitana, promoviendo dinámicas de modernización y de verticalización en los principales barrios de la ciudad (incluido el centro). Pero también -al igual que en el resto de la RMBA- constituyeron un fenómeno de encapsulamiento de los sectores porteños altos y medios, con efectos segregatorios en la ciudad.

Esta reestructuración neoliberal del territorio también tuvo expresión en términos demográficos (Pírez, 2005), delineando una cartografía en la que los sectores medios y medios altos, en general, se concentraron en el cordón centro-norte de la CABA y la RMBA, mientras que los sectores populares lo hicieron preferentemente en el sur y el oeste. Además, se verificó una perificación del proceso de densificación urbana, pues a partir de la última década del siglo XX, y con fuerza desde 2001, el crecimiento poblacional en la primera corona se paralizó, el de la segunda se desaceleró (aunque no dejó de crecer), y el de la tercera se acrecentó (tal como se vio en el apartado anterior) (véase el Mapa 2).

Para cerrar el análisis de esta etapa de desarrollo, es importante remarcar que el neoliberalismo transformó el territorio con una nula orientación pública-estatal, expandiéndose hacia la periferia del primer y segundo cordones del conurbano, y a partir de dos tipos de operaciones (Pírez, 2005, p. 35): unas mercantiles, producto de la planificación y orientadas a sectores de ingresos medios-altos y altos; y otras autoproducidas, individual o colectivamente, para la satisfacción directa de la necesidad habitacional de la población de menores recursos. Por lo anterior, la estructura urbana neoliberal de la RMBA expresó fuertes contrastes sociales plasmados en enclaves tanto de riqueza como de pobreza, asentados en un mismo territorio. $\mathrm{La}$

${ }^{15}$ Veremos más adelante que en la etapa del neodesarrollismo extractivista estas tendencias también se consolidan en las centralidades metropolitanas. 
inclusión / exclusión impresa en el suelo urbano materializó las principales características del modelo de desarrollo neoliberal, pero todo esto se desarrolló en el marco de una fuerte reestructuración de la matriz productiva argentina, que impulsó un proceso de metropolización de bienes, servicios y población.

\section{Mapa 2}

Densificación poblacional, redes de transporte y viejas y nuevas centralidades de la RMBA, 2001

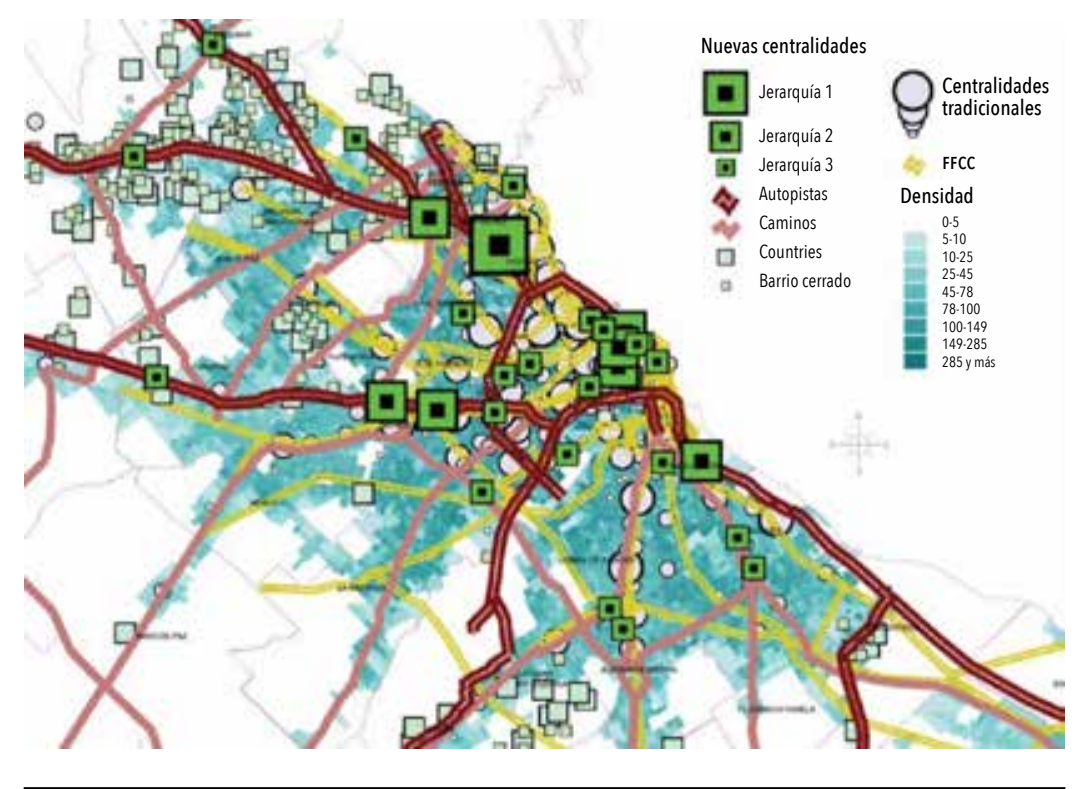

Fuente: Abba, 2011.

\section{Neodesarrollismo extractivista:} ¿una nueva reestructuración del territorio?

El siglo XXI abrió una nueva etapa de acumulación capitalista en Argentina, como también en distintos países de América Latina, a lo que Thwaites Rey y Castillo (2008) llamaron posneoliberalismo (que aquí llamaremos neodesarrollismo extractivista) (López y Vértiz, 2012; Féliz y López, 2010; Svampa, 2011). El nuevo proyecto de desarrollo nacional, desplegado a par- 
tir de la crisis de 2001 y fundamentalmente a partir de la asunción en 2003 de un nuevo gobierno liderado por Néstor Kirchner, ${ }^{16}$ se configuró recuperando y re aggiornando las bases creadas por el neoliberalismo (la transnacionalización del proceso de acumulación), pero a partir de la reproducción de renovadas dependencias vinculadas a la generación de commodities exportables (Svampa, 2011; Féliz y López, 2010), en convivencia con un Estado fuertemente presente a través de políticas sociales compensatorias.

Siguiendo a Treacy (2013) y Gudynas (2009), en la etapa neoliberal las reformas estructurales exigidas por los organismos internacionales de crédito (Banco Interamericano de Desarrollo, Banco Mundial, Fondo Monetario Internacional, entre otros) redujeron al mínimo la intervención estatal en materia económica y social. Esto implicó una extendida liberalización de los flujos de capitales, un recorte significativo de prestaciones sociales y la precarización de las regulaciones laborales, ambientales y territoriales, lo que habilitó el desarrollo de un tipo de extractivismo que incentivó el despliegue de las corporaciones transnacionales. A diferencia de este extractivismo convencional -previo-, las formas de extractivismo que comenzaron a desarrollarse a partir de 2003 en Argentina se dieron de la mano de gobiernos progresistas que intervinieron activamente en el desarrollo económico a través de la renegociación de los contratos, estableciendo nuevas regalías e impuestos, e incluso reorientando la producción directamente desde empresas estatales (como fue el caso de la reestatización de Yacimientos Petrolíferos Fiscales, YPF). Esta mayor presencia del Estado permitió la captura de una mayor porción del excedente económico, el cual fue reorientado hacia políticas sociales compensatorias (Gudynas, 2009) con fuerte impacto social, y se reconfiguró, discursivamente, como una herramienta eficaz para combatir la pobreza y promover el desarrollo.

Para dar cuenta de este proceso, Svampa (2011) plantea que el relato nacional-popular característico del neodesarrollismo coexiste con una política de promoción y convalidación de prácticas abusivas de apropiación y destrucción de los recursos naturales no renovables, sin ningún tipo de consideración por los efectos desestructurantes sobre los pueblos ni los significativos impactos socioambientales. Si bien la retórica oficial presenta un discurso nacional-popular, niega toda referencia al carácter transnacional del gran capital en Argentina (Svampa y Sola Álvarez, 2010) y a la sobreexplotación irresponsable de los recursos naturales (incluido el suelo).

${ }^{16}$ A partir de diciembre de 2003 asumió el nuevo gobierno Néstor Kirchner, quien estuvo en el poder hasta diciembre de 2007; lo sucedió su esposa, Cristina Fernández de Kirchner, por dos periodos consecutivos hasta diciembre de 2015. 
Entonces el neodesarrollismo extractivista, en materia productiva, combinó antiguas estrategias extractivistas de exportación de petróleo o minerales con renovadas dinámicas del neoextractivismo basadas en la agricultura monocultiva -principalmente de soja- producida para la exportación y con prácticas privatizadoras de enajenación de suelo urbano.

En este escenario el suelo adquiere un rol central en tanto factor de producción del ámbito rural, donde se produce una expansión de la frontera agrícola, ${ }^{17}$ como en el ámbito urbano, por el auge en la construcción de nueva vivienda residencial. La creciente demanda de suelo caracteriza los conflictos desplegados a nivel territorial por el acceso a la tierra y por la fuerte precarización de las condiciones habitacionales de los sectores medios y populares. Pintos (2017), retomando a Svampa y Viale (2014), reflexiona -en términos urbanos- sobre la existencia de una articulación de intereses público-privados que, aunque no esté formalizada, tiene efectos concretos y reales en los territorios de las ciudades, pues promueve como estrategias de acumulación la no regulación del mercado de suelo y su posterior liberalización, la concepción de la tierra -y el suelo urbano- como reserva de valor, y la promoción de la especulación inmobiliaria financiera y el desarrollo de megaproyectos inmobiliarios con alto impacto territorial.

Retomando a Azpiazu, Manzanelli y Schorr (2011), es posible identificar ciertas rupturas significativas para el desarrollo del país, pero también determinadas continuidades de peso con el modelo de acumulación previo. En el marco de las primeras, es posible señalar un freno, aunque acotado, al proceso de desindustrialización (a partir del crecimiento de una industria manufacturera liderada por el sector automotriz y metalmecánico con miras a la exportación en el Mercosur), ${ }^{18}$ una significativa creación de puestos de trabajo -aunque muchos de ellos informales y precarizados-, una consecuente mejora en diversos indicadores sociales, un fuerte proceso de desendeudamiento, una reestatización del sistema previsional y un superávit externo y fiscal. Sin embargo, también es posible identificar

${ }^{17}$ La expansión del agronegocio resultó en un corrimiento progresivo de la frontera agropecuaria, que significó la incorporación de tierras que anteriormente eran destinadas a otros cultivos, o directamente no eran rentables para su explotación. Según Teubal (2008), la producción de soja creció entre 1980 y 1996-1997 de 3.7 millones de toneladas a 11 millones, alcanzando los 47.5 millones en 2006-2007. Esto representó más del 50\% de la producción granaria y más del 53\% de la superficie cultivada de granos. La producción sojera (granos, porotos, pellets y derivados) significó el $24.4 \%$ de la exportación total del país en 2007.

${ }^{18}$ No obstante el proceso de industrialización desplegado en estos años, los estudios existentes no verifican cambios estructurales que den cuenta de una reestructuración productiva nacional hacia ramas de mayor dinamismo, de uso intensivo de tecnología o ingeniería, ni tampoco cambios en el perfil exportador de productos industriales del país (Treacy, 2013). 
una serie de continuidades que profundizaron rasgos estructurales de la economía argentina: el mantenimiento del perfil de especialización productivo-industrial y de inserción del país en la división internacional del trabajo, la continuidad de profundas desigualdades sociales y territoriales, el achicamiento de los mercados por procesos de oligopolización, la constante extranjerización de capitales locales, la multiplicación del empleo precario e informal, la existencia de bajos salarios (en una comparación a nivel internacional e histórica), y altibajos inflacionarios. En definitiva, Azpiazu, Manzanelli y Schorr (2011) argumentan que se trata de un neodesarrollismo que agudizó ciertas tendencias vinculadas a la concentración económica y centralización del capital a partir de un proceso de extranjerización de la economía local y una presencia estatal significativa. Esto se logró a raíz de un modelo productivo con marcado perfil primario: extracción y explotación de recursos naturales, expansión de la frontera agrícola y especialización productiva orientada a la exportación. Todo esto mediante el desarrollo de un bajo nivel tecnológico y reducido valor agregado, y un estado interventor con políticas redistributivas.

Por lo anterior, a partir de 2003 muchas de las dinámicas territoriales desarrolladas en la etapa neoliberal encuentran su correlato en el neodesarrollismo extractivista, incluso varias de ellas logran su consolidación, a pesar de la mayor intervención estatal. El desarrollo industrial mostró cierta recuperación en algunos de sus sectores como el alimentario, el textil y el metalmecánico (en un escenario económico de sustitución de importaciones, pero a la vez de exportaciones), y un fuerte auge de la industria pública y privada en la construcción de obra pública y residencial. A nivel territorial, los aparatos productivos de localización tradicional fueron reutilizados y rehabilitados para la reactivación de la actividad industrial (Avellaneda, Lanús, La Matanza, General San Martín -partidos núm. 3, 23, 21 y 17 del Mapa 1, respectivamente- y otros municipios de la primera corona), pero mayoritariamente a partir de nuevos usos orientados a la prestación de servicios vinculados a los nuevos patrones de consumo: hipermercados generales o especializados, campus universitarios, centros logísticos, etc. Incluso, gran parte de las empresas consolidan la tendencia de periferización industrial de la etapa anterior a partir de su traslado de la CABA y el primer cordón del Gran Buenos Aires a la Región Metropolitana de Buenos Aires (segunda corona y, fundamentalmente en esta etapa, a la tercera corona de conurbación). Las inversiones locales (públicas y privadas) y principalmente la inversión extranjera directa, se canalizan hacia la promoción de un nuevo producto del mercado inmobiliario especializado: el parque o zona industrial. Ciccolella y Baer (2008) y Briano, Fritzsche y Vio (2003) 
dan cuenta de un traslado de la mediana-grande y grande industria hacia la periferia más lejana, y del asentamiento de establecimientos medianos-pequeños y pequeños tradicionales al tejido urbano más compacto.

Los parques industriales, reservados sólo a usos industriales y servicios complementarios, consisten en un espacio con infraestructuras y servicios compartidos, gestionados de manera unitaria y diferenciada del tejido habitacional residencial en el que se inserta. El desarrollo de estos parques en la tercera corona se asocia a la existencia de ciertas ventajas de localización, al ofrecimiento de exenciones impositivas y a la disponibilidad de vías de circulación rápida en sus cercanías. Según Briano, Fritzsche y Vio (2003), esta forma de distribución industrial en el territorio no se vinculó al surgimiento de innovaciones en las formas organizativas de la producción, ni a partir de sinergias entre empresas o con actores locales, sino que tiene una explicación netamente inmobiliaria. Los más de veinte parques industriales que actualmente existen en la RMBA se localizan fundamentalmente en los bordes de la tercera corona (Pilar, Zárate, Escobar, La Plata, etc., partidos núm. 31, 41, 10 y 22 en el Mapa 1, respectivamente), pero también algunos en la segunda corona (Malvinas Argentinas, Berazategui, etc., partidos núm. 26 y 4 en el Mapa 1, respectivamente).

En la CABA es posible identificar redes productivas, llamadas "clústeres" o sistemas productivos locales o polos industriales, que concentran algunos segmentos innovadores, tales como: pymes vinculadas a desarrollos científico-tecnológicos (como el Distrito Tecnológico en Parque Patricios o el Polo Farmacéutico en Villa Soldati), industrias culturales (como el Distrito Audiovisual en Palermo y Colegiales, o el Distrito de las Artes en La Boca y San Telmo), actividades turístico-receptivas (desplegadas en La Boca, San Telmo, Palermo o Cañitas) y procesos asociados a la valorización de algunos barrios (considerados "improductivos"). Estas redes productivas cumplieron un rol de peso en la recuperación económica, en la generación de empleo y en el desarrollo económico-territorial (Ciccollela y Vecslir, 2012), produciendo transformaciones urbanas de escala. Estas tendencias visibilizaron la modificación del perfil productivo de la ciudad capital hacia una producción de servicios banales orientados al consumo.

Incluso la Ciudad de Buenos Aires mantuvo durante esta década la monocentralidad y el dinamismo de su área central, reforzada por grandes proyectos urbanísticos como la extensión de Puerto Madero y/o Retiro Puerto, y manteniendo su peso en relación con los subcentros y nuevas centralidades metropolitanas (De Mattos, 1998). Además, en la última década se verificó un proceso de densificación verticalizada y modernización del área central de la ciudad (Microcentro, Plaza San Martín, Catalinas, etc.), que se 
plasmó a partir de importantes obras de reconversión de edificios corporativos a edificios inteligentes.

Este desarrollo del área central de Buenos Aires también se expandió hacia el eje norte del Gran Buenos Aires gracias a la accesibilidad que garantizan avenidas centrales como Del Libertador y Cabildo, la conexión rápida a la autopista y la disponibilidad del subterráneo. Las torres inteligentes en los barrios de la zona norte de la ciudad (Belgrano, Núñez, Saavedra) y las oficinas boutique en Palermo son un claro ejemplo de este desarrollo. Incluso, de manera incipiente todavía, este fenómeno se expande hacia los barrios del Sur, como Barracas y Parque Patricios (véase el Mapa 3).

\section{Mapa 3}

Distritos económicos de la Ciudad de Buenos Aires

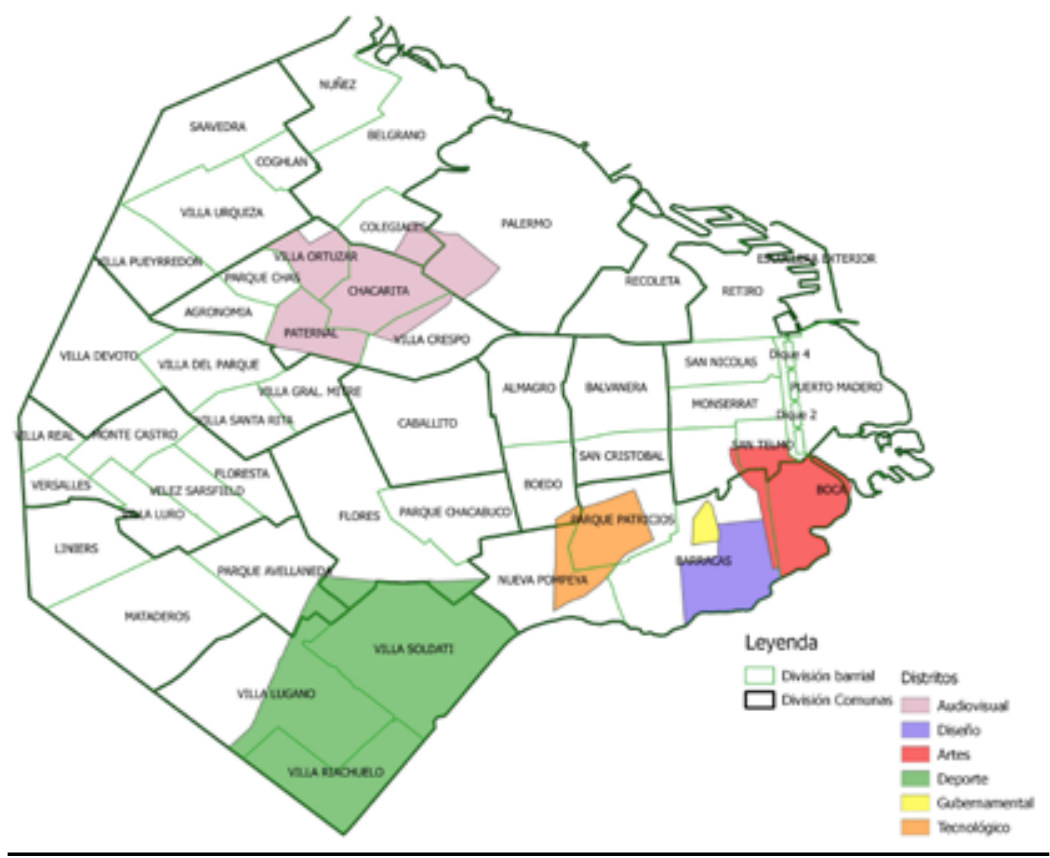

Fuente: Arqueros y González Redondo, 2017.

Otro componente destacado, estimulado en los años de posconvertibilidad, fue la consolidación del desarrollo de procesos de renovación urbana de áreas pericentrales que implicaron la modernización, verticalización, 
densificación y extensión de algunos barrios tradicionales de la CABA (o sectores de los barrios). Tal es el caso de La Boca, Barracas, Parque Patricios, Villa Urquiza, Palermo (véase la localización de barrios en el Mapa 3 ), donde se registraron obras de infraestructura de envergadura (como la extensión de la línea del subterráneo $\mathrm{H}$, la inversión en espacios verdes y públicos de diversa escala, el entubamiento de arroyos subterráneos, etc.) en pos de incorporar estos sectores previamente degradados a segmentos más dinámicos del mercado inmobiliario local y convertirlos en enclaves turísticos, comerciales y residenciales de alto nivel. ${ }^{19}$

En paralelo, otra tipología habitacional innovadora de la CABA fueron las torres de alto standing (Ciccollela y Vecslir, 2012) desarrolladas en barrios de origen residencial de sectores medios. Se trata de torres nuevas, equipadas con servicios comunes o amenities que cambian totalmente la fisonomía y población de sus barrios de inserción y son ofrecidas a la venta o alquiler mediante el mercado. Si bien fueron novedad en la etapa neoliberal, logran su expansión en los años 2000 a partir de la conversión de la construcción de vivienda nueva en una de las principales estrategias de inversión, e incluso reserva de valor. No obstante, a escala barrial, dichas transformaciones generaron conflictos con la población previamente localizada allí, que veía colapsar las infraestructuras de servicios y reducirse al mínimo los espacios verdes de sus zonas.

Inclusive, en la primera década de este siglo este fenómeno se expandió hacia el Gran Buenos Aires, principalmente en algunas cabeceras departamentales, las cuales se densificaron y registraron un proceso de verticalización residencial de sus centros tradicionales ya consolidados. Así, las zonas céntricas de algunos municipios del sur de la primera y de la segunda coronas de la RMBA (como Quilmes, Lomas de Zamora, Esteban Echeverría, partidos núm. 33, 24 y 11 respectivamente en el Mapa 1) vieron modernizado su parque habitacional central a través de dichos inmuebles, que se presentaron como una alternativa al formato que proponen las urbanizaciones cerradas. Incluso esta transformación de zonas tradicionales del conurbano estimuló la renovación de los usos y funciones de estos espacios, dando origen a una gastronomía especializada, instalación de cafés boutique, comercios de diseño e indumentaria de primeras marcas, oficinas con renovado y tecnificado equipamiento, etcétera.

Ahora bien, como se dijo, en competencia con estas torres de alto standing en las subcentralidades del conurbano, y en pleno despliegue de un

${ }^{19}$ Para profundizar en procesos de renovación de la ciudad en Buenos Aires, se pueden revisar los siguientes textos: Herzer, 2008; Carbajal, 2003; Zapata y Belluscio, 2018. 
proceso de suburbanización residencial, se consolidan las ya tradicionales urbanizaciones cerradas de la etapa anterior (countries, barrios cerrados, clubes de campo, condominios, etc.), orientadas a los sectores medios-altos y altos. Ciccolela y Vesclir $(2012$, p. 34) registran para esos años "unas 574 UC [unidades cerradas], de las cuales 20 serían megaemprendimientos", como el Nordelta en la zona norte y el Nuevo Quilmes en la zona sur del conurbano. Y de la mano de estas urbanizaciones "americanizantes", la reactivación económica de la época estimuló la actividad y apertura de grandes centros de consumo (tipo shopping a cielo abierto, hipermercados, centros comerciales y de entretenimiento, etc.), que siguieron la tendencia a la periferización de las urbanizaciones cerradas. Ciccolella y Baer (2009) afirman que en los últimos años el Gran Buenos Aires ejerció mayor atracción a la instalación de grandes centros de consumo que la ciudad capitalina, por lo que el proceso de suburbanización que se registró en las últimas décadas ya no remite exclusivamente al ámbito residencial, sino que incorpora progresivamente nuevos espacios de actividades y de trabajo vinculados al comando empresarial, al ocio, al consumo, al comercio y a los servicios para la producción y para las personas (Vesclir y Ciccolella, 2011).

Pero al mismo tiempo que se consolidaron estos enclaves de riqueza, proliferaron los de pobreza. El crecimiento de formas de hábitat popular informal en villas y asentamientos y el desarrollo extendido de un mercado inmobiliario informal fueron características propias de la última década (Rodríguez, Rodríguez y Zapata, 2018). Sólo en la CABA, de acuerdo al censo 2010, la población villera creció $52.3 \%$ (de 107422 habitantes en 2001 a 163587 en 2010), mayormente localizada en la zona sur capitalina. Según la organización Un Techo para mi País (2011), en la RMBA existen 864 villas y asentamientos, donde viven 508144 familias. A partir de un fuerte proceso de densificación de los barrios (de 55.6\%), entre 2000 y 2011 se registró un aumento de $16.7 \%$ de su población. En cuanto al acceso a los servicios básicos, el $85.2 \%$ de los barrios relevados del conurbano no cuentan con acceso a la red cloacal y el $83.4 \%$ no tienen acceso a la red de gas. Además, a la informalidad en la tenencia del suelo hay que adicionarle que estos barrios presentan diversas carencias en la estructura familiar-laboral, en el nivel de accesibilidad al transporte público y en las condiciones de habitabilidad de sus viviendas. Según el informe, los municipios con mayor cantidad de barrios informales fueron: La Matanza, Quilmes, Moreno, Pilar, Merlo y Florencio Varela (partidos núm. 21, 33, 29, 31, 28 y 14 en el Mapa 1).

Los fuertes contrastes territoriales que se profundizaron en la última década también provocaron importantes conflictos por la disputa sobre el acceso al suelo y a la vivienda entre los distintos sectores de la sociedad. La 
toma del Parque Indoamericano en diciembre de 2010 por parte de sectores populares e inquilinos informales de villas y asentamientos (Ferme, Vera y Zapata, 2014; Zapata, 2013), en contraste con las más de 225 mil viviendas ociosas existentes en la ciudad -según el censo de 2010-, visibilizó de manera dramática la desigualdad sociourbana proliferante. La disputa por el suelo asumió entonces una importancia determinante en términos de dinamizador del nuevo régimen de acumulación neodesarrollista, pues el auge inmobiliario que experimentó la ciudad con la posconvertibilidad ejerció una presión inédita sobre la accesibilidad al suelo y a la vivienda, que no sólo restringió el acceso a la vivienda vía el mercado a los sectores con cierta capacidad adquisitiva, sino incluso limitó la disponibilidad de suelo para la construcción de vivienda social por parte del Estado (Ciccolella y Baer, 2009).

Por último, en materia de política habitacional, el Estado nacional recobró la iniciativa de producción de vivienda social para los sectores medios y bajos mediante una cartera de planes federales de vivienda (Programa de Emergencia Habitacional "Techo y Trabajo", Programa Federal de Construcción de Viviendas I y II, Programa de Mejoramiento de Barrios, Programa Federal de Mejoramiento Habitacional y, más recientemente, Programa de Créditos de Argentina -Procrear-). No obstante la masiva intervención por parte del Estado, esta política no se implementó de manera articulada con un plan de ordenamiento territorial de aquellas localidades donde se ejecutaron los programas. Esto trajo como consecuencia que las nuevas viviendas construidas se localicen en malas ubicaciones, con poca accesibilidad e incluso, en muchos casos, sin dotación previa de servicios de infraestructura social y urbana (Ostuni, 2009). Por lo anterior, el Estado sólo logró construir viviendas en aquellas localizaciones en las que el mercado no tenía ningún tipo de interés, reforzando los procesos de segregación sociourbana para las familias destinatarias.

Para cerrar con el análisis de esta fase de desarrollo, el neodesarrollismo extractivista recupera las bases de acumulación del modelo anterior, pero reorientándose hacia la generación de commodities exportables con una presencia estatal fuerte en materia de políticas sociales compensatorias. Esto se tradujo a escala territorial en cierta recuperación de la matriz productiva en algunos sectores específicos que suburbanizaron sus localizaciones en nuevos formatos industriales (hacia la tercera corona de la RMBA) y se reorientó el desarrollo de la CABA hacia una industria orientada al consumo y a la prestación de servicios, con formatos de distritos económicos. En materia de condiciones de habitabilidad, se verificó una extensión de la brecha entre los que accedieron a la vivienda a través del mercado y/o el Estado y los que tuvieron que hacerlo mediante la producción social del 


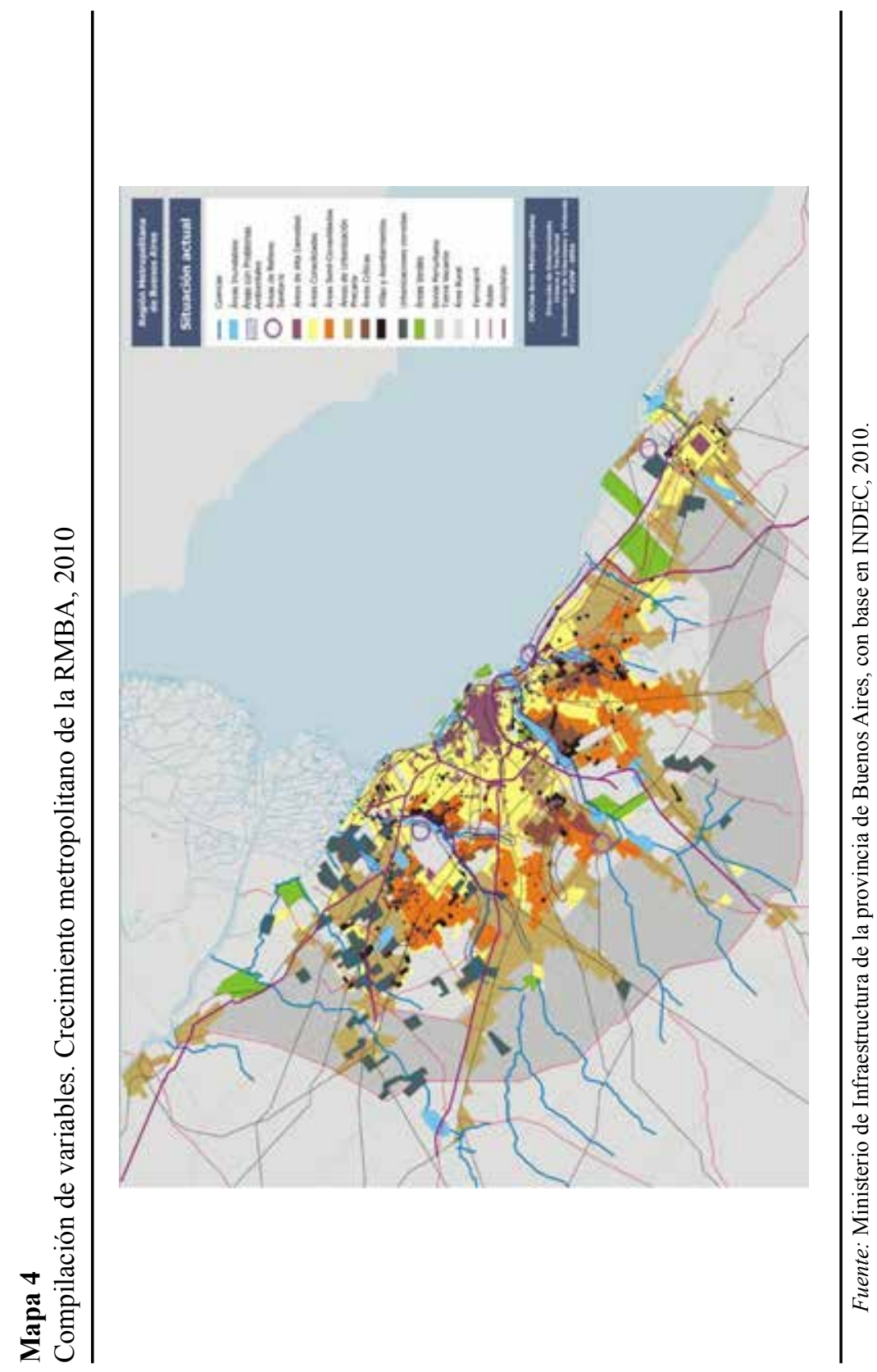


hábitat, expresándose en una mayor dualización social y segregación sociourbana.

\section{Algunas reflexiones finales}

Este artículo buscó analizar la expresión territorial de la transición del modelo productivo neoliberal al nuevo modelo neodesarrollista extractivista de la posconvertibilidad, desplegados desde los años setenta en Argentina. Específicamente, se trató de rastrear las continuidades y rupturas en la estructura social y urbana en la RMBS, en pos de analizar cómo se desempeñó la triple relación estado- mercado- sociedad en el territorio. Para ello, primeramente, se caracterizó geográficamente el área de estudio (la RMBA). Luego se describieron en términos políticos y económicos tanto el modelo de desarrollo neoliberal como el neodesarrollista extractivista para, a continuación, interpretar los reacomodamientos que se generaron a escala territorial.

Lo que se verificó a lo largo del artículo es que la matriz sociourbana de la RMBA sufrió una fuerte transformación con la instalación del neoliberalismo en los años setenta y fundamentalmente en los noventa. No obstante, con el devenir de una nueva fase de desarrollo en la primera década del presente siglo no se constataron modificaciones sustanciales a escala territorial, a pesar de las fuertes mutaciones que sufrió el sistema de acumulación en términos políticos y económicos. Por el contrario, en dicha década se afianzaron las principales tendencias de la ciudad neoliberal y el rol funcional de las mencionadas transformaciones en la reestructuración del modelo de acumulación. La intervención estatal en el territorio fue, a lo largo de las últimas tres décadas y media, subsidiaria de los intereses del capital concentrado y especulativo, reproduciendo la lógica de producción de la ciudad planificada y desarrollada por el mercado y -un estado- actuando ex post (en algunos casos) ante la producción social del hábitat desplegado por parte de los sectores populares.

La articulación de intereses público-privados en materia urbana se expresó en términos también extractivistas a partir de la promoción de fuertes y concentrados procesos de desregulación del mercado de suelo -y su posterior liberalización- y la conversión del suelo urbano en reserva de valor. Esto promovió dinámicas extendidas de especulación inmobiliaria y financiera en la Ciudad de Buenos Aires y en los partidos cabeceras del conurbano, y el desarrollo de megaproyectos inmobiliarios con alto impacto territorial en la colateral generación de procesos segregatorios. 
En materia industrial, en la última etapa se dio un reforzamiento del proceso de suburbanización de algunas ramas industriales en el tercer cordón de la RMBA en formatos renovados, pero además fueron acompañados de la instalación progresiva de nuevos espacios de actividades y de trabajo vinculados al comando empresarial, al ocio, al consumo, al comercio y a los nuevos espacios residenciales. Esto visibiliza una modificación paulatina de las tendencias en el uso del espacio de la urbe, contribuyendo a la formación de subcentros metropolitanos que presentan características de complementariedad con la centralidad tradicional de la CABA y los antiguos centros departamentales de la región.

$\mathrm{Al}$ igual que en la década del noventa, el neodesarrollismo extractivista generó un reforzamiento de nuevos sectores medios-altos con un patrón de autosegregación territorial en torres en la ciudad y en unidades cerradas en la periferia, y el resurgimiento de conflictos nuevamente vinculados a la incapacidad de acceso a la vivienda (densificación de asentamientos y villas, ocupaciones de inmuebles y desalojos forzados). No obstante, en contraste con la década anterior, la mayor participación estatal del neodesarrollismo tuvo por resultado intervenciones focalizadas en el acceso a la vivienda y la provisión de ciertos servicios y equipamientos, pero fueron insuficientes para revertir el agravamiento de las condiciones del hábitat popular por la falta de una política de regulación del suelo. Las contradicciones de dicho proceso mostraron, por un lado, tendencias hacia la renovación y globalización de ciertos fragmentos territoriales de la RMBA, pero, por otro, evidenciaron la profundización de la exclusión social y la fragmentación del territorio metropolitano.

\section{Bibliografía}

Abba, A. P. (2011). Uso de suelo y transporte en la Buenos Aires metropolitana. Voces en el Fénix. 9, 84-93. Recuperado de http://www.voces enelfenix.com/sites/default/files/pdf/12_1.pdf

Abramo, P. (2003). A cidade da informalidade: o desafio das cidades latino-americanas. Río de Janeiro, Brasil: Livraria Sette Letras / FAPERJ. Argumedo, A. (2000). El imperio del conocimiento. Encrucijadas, 1(2), 177186. Recuperado de https://es.scribd.com/doc/104645662/ArgumedoAlcira-El-Imperio-Del-Conocimiento

Arqueros, S. y González Redondo, C. (2017). La política de distritos del sur de Buenos Aires: una mirada en perspectiva. Quid 16, 7, 7-29. Recupe- 
rado de https://publicaciones.sociales.uba.ar/index.php/quid16/article/ view/2851/pdf_7

Azpiazu, D., Manzanelli, P. y Schorr, M. (2011). Concentración y extranjerización. La Argentina en la postconvertibilidad. Buenos Aires, Argentina: Capital Intelectual.

Balbo, M., Porto, G. y Posadas, J. (1996). Concentración territorial de la industria en la Argentina (Cuadernos de Economía, 22). La Plata, Buenos Aires: Ministerio de Economía de la Provincia de Buenos Aires.

Brailovsky, A. y Foguelman, D. (2004). Memoria verde. Historia ecológica de la Argentina. Buenos Aires, Argentina: Sudamericana.

Borello, J. A., Vio, M., Fritzsche, F. y Bottaro, L. (2000). La geografía de la industria en la Región Metropolitana de Buenos Aires. Un análisis de los datos de los dos últimos censos económicos (1985-1994). (Informe de Investigación. núm. 10). Polvorines, Argentina: Universidad Nacional General Sarmiento.

Briano L., Fritzsche, F. y Vio, M. (2003). El lugar de la industria. Los parques industriales en la reestructuración productiva y territorial de la Región Metropolitana de Buenos Aires. Eure, Revista Latinoamericana de Estudios Urbano Regionales, 29(86), 109-135. Recuperado de https://scielo.conicyt.cl/scielo.php?script=sci_arttext\&pid=S02 50-71612003008600006

Carbajal, R. (2003). Transformaciones socioeconómicas y urbanas en Palermo. Revista Argentina de Sociología, 1(1), 94-109. Recuperado de https://www.redalyc.org/pdf/269/26900107.pdf

Ciccolella, P. (1999). Globalización y dualización en la región metropolitana de Buenos Aires. Grandes inversiones y reestructuración socio-territorial en los años noventa. Eure, Revista Latinoamericana de Estudios Urbano Regionales, 25(76), 5-27. Recuperado de https://scielo.conicyt. cl/scielo.php?script=sci_arttext\&pid=S0250-71611999007600001

Ciccolella, P. y Baer, L. (2008). Buenos Aires tras la crisis: ¿hacia una metrópolis más integradora o más excluyente? Ciudad y Territorio: Estudios Territoriales, 40(158), 641-660. Recuperado de https://dialnet. unirioja.es/servlet/articulo?codigo $=2795576$

Ciccolella, P. y Baer, L. (2009). Crecimiento económico y estructuración metropolitana. Continuidades y discontinuidades en el desarrollo territorial de la RMBA entre 1990 y 2007. Ponencia presentada en el XII Encuentro de Geógrafos de América Latina. Montevideo, Uruguay.

Ciccollela, P. y Vecslir, L. (2012). Dinámicas, morfologías y singularidades en la reestructuración metropolitana de Buenos Aires. riURB, Revista 
Iberoamericana de Urbanismo, 8, 23-41. Recuperado de https://core. ac.uk/download/pdf/41789954.pdf

Cravino, M. C. (2006). Las villas de la ciudad. Mercado e informalidad urbana. Los Polvorines, Buenos Aires: Universidad Nacional de General Sarmiento.

Cravino, M. C., Del Río, J. P. y Duarte, J. (2008). Magnitud y crecimiento de las villas y asentamientos en el área metropolitana de Buenos Aires en los últimos 25 años. Ponencia presentada en el XIV Encuentro de la Red Universitaria Latinoamericana de Cátedras de Vivienda. Argentina: Universidad de Buenos Aires, Facultad de Arquitectura, Urbanismo y Diseño.

Cuenya, B. (2000). Cambios, logros y conflictos en la política de vivienda en Argentina hacia fines del siglo XX. Ponencia presentada en el Seminario Internacional Gestión Local y Políticas Habitacionales. Argentina: Universidad de Mar del Plata / Universidad Nacional de Rosario. Recuperado de http://habitat.aq.upm.es/boletin/n29/abcue.html\# fntext-1

Davidson, M. (2008). Spoiled mixture: Where does state-led positive gentrification end? Urban Studies, 45(12), 2385-2405. Recuperado de https://journals.sagepub.com/doi/pdf/10.1177/0042098008097105

De Mattos, C. (1998). Reestructuración, crecimiento y expansión metropolitana en las economías emergentes latinoamericanas. En S. Gorenstein y R. Cara Bustos (comps.), Ciudades y regiones frente al avance de la globalización (pp. 723-753). Bahía Blanca, Argentina: Universidad Nacional del Sur.

De Mattos, C. A. (2010). Globalización y metamorfosis metropolitana en América Latina. De la ciudad a los urbano generalizado. Revista de Geografia Norte Grande, 47, 81-104. Recuperado de http://dx.doi. org/10.4067/S0718-34022010000300005

Féliz, M. (2012). Neoextractivismo, neodesarrollismo y proceso de acumulación de capital: ¿superando el ciclo stop and go? Argentina 20032012. Ponencia presentada en las VII Jornadas de Sociología de la Universidad Nacional de La Plata. La Plata, Argentina, 5 a 7 de diciembre.

Féliz, M. y López, E. (2010). La dinámica del capitalismo periférico postneoliberal neodesarrollista. Contradicciones, barreras y límites de la nueva forma de desarrollo en la Argentina. Herramienta. Revista de Debate y Crítica Marxista, 45, 109-124. Recuperado de http://www. memoria.fahce.unlp.edu.ar/art_revistas/pr.4654/pr.4654.pdf 
Ferme, N., Vera, L. y Zapata, M. C. (2014). La toma del Parque Indoamericano. Un disparador para pensar a la política pública en movimiento. Revista Perspectiva de Políticas Públicas, 3(6), 101-125. Recuperado de http://cmvilas.com.ar/index.php/rppp/122-n6-revista-perspectivasde-politicas-publicas

Fritzsche, F. y Vio, M. (2005). La huella del desarrollo urbano en la Región Metropolitana de Buenos Aires. Consideraciones acerca de las transformaciones recientes del espacio industrial. Scripta Nova. Revista Electrónica de Geografía y Ciencias Sociales, 9(194). Recuperado de http://www.ub.edu/geocrit/sn/sn-194-113.htm

García Delgado, D. (1994). Estado y sociedad. La nueva relación a partir del campo estructural. Buenos Aires, Argentina: Flacso-Sociales.

González, M. E. (2002). La dictadura militar (1976-1983). En R. González Lebrero (coord.), Sociedad, política y economía en la Argentina contemporánea. Un esbozo histórico (pp. 129-141). Buenos Aires, Argentina: Montaldo.

Gudynas, E. (2009). Diez tesis urgentes sobre el nuevo extractivismo. Contextos y demandas bajo el progresismo sudamericano actual. En Centro Andino de Acción Popular y Centro Latinoamericano de Ecología Social (eds.), Extractivismo, política y sociedad (pp. 187-225). Quito, Ecuador: Centro Andino de Acción Popular / Centro Latinoamericano de Ecología Social (Cuadernos de Capacitación).

Harvey, D. (2000). Espacios de esperanza. Madrid, España: AKAL.

Herzer, H. (2008). Con el corazón mirando al sur: transformaciones en el sur de la Ciudad de Buenos Aires. Buenos Aires, Argentina: Espacio.

INDEC (2010). Censo Nacional de Población Hogares y Viviendas 2010. Buenos Aires, Argentina: Instituto Nacional de Estadística y Censos. Recuperado de www.indec.gov.ar

Instituto del Conurbano (2016). Delimitación que toma en cuenta la cobertura de las actividades económicas y la movilidad cotidiana de la población, que incluye a la Ciudad de Buenos Aires y 40 partidos, aproximadamente. Polvorines, Argentina: Universidad Nacional General Sarmiento. Recuperado de http://observatorioconurbano.ungs.edu. ar/?page_id $=2708$

Herzer, H. y Pírez, P. (1994). Gestión urbana en ciudades de tamaño medio de América Latina. Nairobi, Kenia: Hábitat-ONU.

López, E. y Vértiz, F. (2012). Capital transnacional y proyectos nacionales de desarrollo en América Latina. Las nuevas lógicas del extractivismo neodesarrollista. Herramienta. Revista de Debate y Critica Marxista, 
16(50), 1-11. Recuperado dehttps://biblat.unam.mx/hevila/Herramienta BuenosAires/2012/no50/2.pdf

Merklen, D. (1991). Asentamientos en La Matanza. La terquedad de lo nuestro. Buenos Aires, Argentina: Catálogos Editora.

Ostuni, F. (2009). Políticas habitacionales nacionales y escenarios locales. Aproximaciones a la implementación del Programa Federal de Construcción de Viviendas en la Ciudad de Buenos Aires (Tesis de maestría en Administración Pública, Universidad de Buenos Aires, Facultad de Ciencias Sociales).

Oszlak O. (1991). Merecer la ciudad. Los pobres y el derecho al espacio urbano. Buenos Aires, Argentina: Estudios CEDES-Humanitas.

Oszlak, O. y O'Donnell, G. (1981). Estado y políticas estatales en América Latina: hacia una estrategia de investigación. Redes, 2(4), 99-128. Recuperado de https://www.redalyc.org/pdf/907/90711285004.pdf

Pintos, P. (2017). El extractivismo inmobiliario y vulneración de bienes comunes en la cuenca baja del río Luján. En A. M. Vásquez Duplat (comp.), Extractivismo urbano: debates para una construcción colectiva de las ciudades (pp. 23-39). Buenos Aires, Argentina: El Colectivo / Centro de Estudios y Acción por la Igualdad / Fundación Rosa Luxemburgo.

Pírez, P. (2005). Expansión territorial, privatización y fragmentación en la configuración de Buenos Aires. Cadernos Metrópole, 13, 11-46. Recuperado de http://ffyll.uncu.edu.ar/IMG/pdf/PIREZ-2005-Expans_ territ_y_fragmentac_en_aa_metrop_de_BAs.pdf

Rodríguez, M. C. (2005). Como en la estrategia del caracol. Ocupaciones de edificios y políticas locales del hábitat en la Ciudad de Buenos Aires. Buenos Aires, Argentina: El Cielo por Asalto.

Rodríguez, M. C., Rodríguez, M. F. y Zapata, M. C. (2018). Mercantilización y expansión de la inquilinización informal en villas de Buenos Aires, Argentina. Revista INVI, 34(93), 125-150. Recuperado de https://scielo. conicyt.cl/pdf/invi/v33n93/0718-8358-invi-33-93-125.pdf

Rousseau, M. (2009). Re-imaging the city centre for the middle classes: Regeneration, gentrification and symbolic policies in loser cities. International Journal of Urban and Regional Research, 33(3), 770-788. Recuperado de https://onlinelibrary.wiley.com/doi/full/10.1111/j.14682427.2009.00889.x

Sánchez, A. (2012). Del derecho a la vivienda al derecho a la ciudad. Barcelona, España: Observatorio Derechos Económicos, Sociales y Culturales. 
Subsecretaría de Urbanismo y Vivienda. (2007). Lineamientos estratégicos para la Región Metropolitana de Buenos Aires. Buenos Aires, Argentina: Dirección Provincial de Ordenamiento Urbano y Territorial.

Svampa, M. (2011). Extractivismo neodesarrollista y movimientos sociales. ¿Un giro ecoterritorial hacia nuevas alternativas? En M. Lang y D. Mokrani (coord.), Mas allá del desarrollo (pp. 185-218). Quito, Ecuador: Abya Yala.

Svampa, M. y Sola Álvarez, M. (2010). Modelo minero, resistencias sociales y estilos de desarrollo: los marcos de la discusión en la Argentina. Ecuador Debate, 79, 105-126. Recuperado de http://repositorio.flacsoandes. edu.ec/bitstream/10469/3526/1/RFLACSO-ED79-07-Svampa.pdf

Svampa, M. y Viale, E. (2014). Maldesarrollo: la Argentina del extractivismo y el despojo. Buenos Aires, Argentina: Katz.

Techo. (2016). Relevamiento de asentamientos informales (Documento de Trabajo). Argentina. Recuperado de https://issuu.com/techoargentina/ docs/rai_2016____ltima_versi_n

Teubal, M. (2008). Soja y agronegocios en la Argentina: la crisis del modelo. Lavboratorio. Revista de Estudios sobre Cambio Estructural y Desigualdad Social, 22, 5-7. Recuperado de https://publicaciones.sociales. uba.ar/index.php/lavboratorio/article/view/92

Thwaites Rey, M. y Castillo, J. (2008). Desarrollo, dependencia y Estado en el debate latinoamericano. Araucaria: Revista Iberoamericana de Filosofia, Politica y Humanidades y Relaciones Internacionales, 10(19), 24-45. Recuperado de http://institucional.us.es/revistas/Araucaria/ A\%C3\%B10\%2010\%20\%20N\%C2\%BA\%2019\%20\%202008/ Mabel\%20Thwaites\%20Rey_Jos\%C3\%A9\%20Castillo.pdf

Treacy, M. (2013). Neodesarrollismo, extractivismo y problemáticas ambientales en la Argentina (2002-2013). Ponencia presentada en las II Jornadas de Pensamiento Crítico Latinoamericano, "Capitalismo en el nuevo siglo: el actual desorden mundial”. Río Cuarto, Argentina: Universidad Nacional de Río Cuarto.

Un Techo para mi País. (2011). Relevamiento de villas y asentamientos en el Gran Buenos Aires. Recuperado de http://datospublicos.org/package/ relevamiento-de-villas-y-asentamientos-en-el-gran-buenos-2011aires

Verón, M., Adamo, S. y Tobio, D. (1998). Algunos efectos geográficos de la globalización en la Argentina. En Geografia. Documentos para la Capacitación Docente (pp. 101-103). Buenos Aires, Argentina: Universidad Nacional de General San Martín.

Vesclir, L. y Ciccolella, P. (2011). Relocalización de las actividades terciarias y cambios en la centralidad en la Región Metropolitana de 
Buenos Aires. Revista de Geografia Norte Grande, 49, 63-78. Recuperado de https://scielo.conicyt.cl/scielo.php?script=sci_arttext\&pid= S0718-34022011000200005

Yujnovsky, O. (1984). Claves politicas del problema habitacional argentino 1955-1981. Buenos Aires, Argentina: Grupo Editor Latinoamericano.

Zapata, M. C. (2011). Expresiones territoriales de los diversos modelos socio-económicos de país (Cuadernillo de Cátedra Brailovsky). Buenos Aires, Argentina: Universidad de Buenos Aires. Recuperado de http://www. sociedad-estado.com.ar/wp-content/uploads/2012/03/Expresiones $\% 20$ territoriales.pdf

Zapata, M. C. (2012). El Programa de Autogestión para la Vivienda: ¿una política habitacional habilitante del derecho a la vivienda y a la ciudad? (Tesis de maestría en Administración Pública, Universidad de Buenos Aires, Facultad de Ciencias Económicas). Recuperado de http://biblioteca.clacso.edu.ar/Argentina/iigg-uba/20120802051652/ czapata.pdf

Zapata, M. C. (2013). Toma de tierras en la Ciudad de Buenos Aires. Un análisis de las causas estructurales que anunciaron el conflicto del Parque Indoamericano. Pampa. Revista Interuniversitaria de Estudios Territoriales, 9, 45-71. Recuperado de https://dialnet.unirioja.es/descarga/ articulo/4660648.pdf

Zapata, M. C. (2017). La política habitacional porteña bajo la lupa de los programas llave en mano a la autogestión del hábitat. Buenos Aires, Argentina: Teseo.

Zapata, M. C. y Belluscio, S. (2018). De la Autopista 3 al Barrio Parque Donado-Holmberg (Buenos Aires, Argentina): una larga disputa por el espacio urbano. Quid 16, 9, 60-90. Recuperado de http://publicaciones. sociales.uba.ar/index.php/quid16/article/view/2807/pdf_21

\section{Acerca de la autora}

María Cecilia Zapata es doctora en Ciencias Sociales, maestra en Administración Pública y licenciada y profesora en Sociología, todo por la Universidad de Buenos Aires (UBA). Actualmente es investigadora del Consejo Nacional de Investigaciones Científicas y Técnicas, adscrita al Área de Estudios Urbanos del Instituto de Investigación Gino Germani, UBA; en dicha universidad también ejerce actividades de docencia. Se especializa en el estudio de políticas habitacionales, producción social del hábitat y procesos 
de trasformación urbana en el Área Metropolitana de Buenos Aires, con énfasis en el análisis de las distintas modalidades de acceso al hábitat por parte de los sectores populares. ORCID: http://orcid.org/0000-0003-0580-6938

Entre sus publicaciones se encuentran:

Zapata, M. C. (2020). La participación social en la reurbanización de villas. ¿Prácticas habilitantes del derecho a la ciudad? Bitácora Urbano Territorial, 30(1), 91-102. Recuperado de https://doi.org/10.15446/bitacora. v30n1.82559

Rodríguez, M. C., Rodríguez, M. F. y Zapata, M. C. (2018). Mercantilización y expansión de la inquilinización informal en villas de Buenos Aires, Argentina. Revista Invi, 33(93), 125-150. Recuperado de http:// dx.doi.org/10.4067/S0718-83582018000200125

Zapata, M. C. y Belluscio, S. (2018). De la Autopista 3 al Barrio Parque Donado-Holmberg (Buenos Aires, Argentina): una larga disputa por el espacio urbano. Quid 16, 9, 60-90. Recuperado de https://publicaciones. sociales.uba.ar/index.php/quid16/article/view/2807

Recepción: 5 de septiembre de 2018. Aceptación: 9 de enero de 2019. 